\title{
The efficacy of pregabalin for the management of postoperative pain in primary total knee and hip arthroplasty: a meta-analysis
}

Fei $\mathrm{Li}^{1,2+}$, Jianxiong Ma ${ }^{1 *+}$, Mingjie Kuang ${ }^{1 \dagger}$, Xuan Jiang ${ }^{1}$, Ying Wang ${ }^{1}$, Bin $\mathrm{Lu}^{1}$, Xingwen Zhao ${ }^{1}$, Lei Sun ${ }^{1}$ and Xinlong $\mathrm{Ma}^{1 *}$

\begin{abstract}
Objective: A systematic review of randomized controlled trials (RCTs) was conducted to evaluate the efficacy of pregabalin for the management of postoperative pain in patients undergoing primary total knee arthroplasty (TKA) and primary total hip arthroplasty (THA).

Method: The PubMed, Embase, Cochrane Central Register of Controlled Trials, and Google Scholar databases were searched for related articles using search strategy. RevMan 5.3 software was selected to conduct the meta-analysis.

Results: Seven RCTs were included in our meta-analysis. There were significant differences in visual analogue scale (VAS) at 24 and $48 \mathrm{~h}$ with rest, knee flexion degree, mean morphine consumption, and postoperative side effects (nausea, vomiting, pruritus, and dizziness) when comparing the pregabalin group to the placebo group after TKA and THA. However, the differences in VAS at $72 \mathrm{~h}$ with rest and at $24 \mathrm{~h}$ on movement were not significant between the two groups.

Conclusions: Pregabalin was found to improve pain control at 24 and $48 \mathrm{~h}$ with rest, reduce morphine consumption, improve the knee flexion degree, decrease the incident rate of nausea, vomiting, and pruritus, and increase the incident rate of dizziness after TKA and THA but could not improve the pain control at $72 \mathrm{~h}$ with rest. In summary, the use of pregabalin may be a valuable asset in pain management within the first $48 \mathrm{~h}$ after TKA and THA. However, future studies regarding doses and pregabalin medication are required.
\end{abstract}

Keywords: Pregabalin, Arthroplasty, Meta-analysis, Pain

\section{Background}

Total knee arthroplasty (TKA) and total hip arthroplasty (THA) have become common treatments for patients with severe knee and hip functional impairment. These surgeries can significantly relieve pain, restore joint function, and improve quality of life $[1,2]$. The number of patients undergoing TKA and THA has increased steadily each year, and this trend will continue in the foreseeable future due to the aging of the population [3].

\footnotetext{
* Correspondence: majianxiong957@163.com; maxinlong4787@163.com ${ }^{\dagger}$ Equal contributors

${ }^{1}$ Biomechanics Labs of Orthopaedics Institute, Tianjin Hospital, Tianjin 300050, People's Republic of China

Full list of author information is available at the end of the article
}

Postoperative pain after total joint arthroplasty has remained a serious problem, which prolongs length of hospital stay and functional recovery. Therefore, appropriate pain management protocol is necessary to relieve postoperative pain and achieve early functional recovery.

Opioids have generally been used for pain control after TKA or THA. However, common side effects, such as sedation, dizziness, nausea, vomiting, constipation, physical dependence, tolerance, and respiratory depression, are serious problems with these medications $[4,5]$. Pregabalin is a structural analog of $\gamma$-aminobutyric acid (GABA) that acts on the $\alpha 2 \delta$ subunit of voltagedependent calcium channels, which can reduce the release of neurotransmitters [6-8]. Although it was 
approved for the treatment of partial seizures, pregabalin has been administered for other indications, such as fibromyalgia, diabetic neuropathy, and even acute postsurgical pain [9].

In recent years, some randomized controlled trials (RCTs) have been carried out to evaluate the effects of pregabalin. However, different conclusions have been reached, and the efficacy of pregabalin for pain management among TKA and THA patients has remained unclear. Jain et al. [10] reported that perioperative administration of pregabalin reduced opioid consumption, improved postoperative analgesia, and yielded higher patient satisfaction levels in primary TKA. However, Singla et al. [11] showed that there was no significant difference between pregabalin and placebo with respect to the worst pain $(24 / 48 \mathrm{~h}$ postsurgery) after TKA. Similar conclusions have been reached by YaDeau [12]. Therefore, the role of pregabalin for pain control and functional recovery after TKA and THA has not been investigated in systematic review and meta-analysis. This meta-analysis was conducted to determine whether pregabalin used systematically can decrease postoperative pain and improve joint function when compared with placebo.

\section{Materials and method}

\section{Search strategy}

The PubMed (1980-July 2016), Embase (1980-July 2015), Cochrane Central Register of Controlled Trials, and Google Scholar databases were searched for related articles using the search strategy outlined in Appendix 1. According to the Cochrane Collaboration guidelines, we also conducted other database searches. The search strategy is presented in Fig. 1.

\section{Study selection}

Included studies were considered eligible if they met the following criteria:

Study design: Interventional studies

Population: Patients were scheduled for primary TKA and THA

Intervention: Pregabalin

Comparator: Placebo or nothing

Outcome:

Primary outcome: Visual analogue scale (VAS) at 24, 48 , and $72 \mathrm{~h}$ with rest and at $24 \mathrm{~h}$ on movement and morphine consumption

Secondary outcome: Knee flexion degree and treatment side effects (nausea, vomits, pruritus and dizziness)

\section{Quality assessment}

Published RCTs comparing pregabalin with a control (placebo or nothing) in patients who underwent primary TKA or THA are included in this meta-analysis. The eligibility assessment was conducted by two reviewers (F.L. and JX.M.) independently in an unblended standardized manner. Disagreements were resolved by consensus. According to the Cochrane Handbook for Systematic Reviews of Interventions [13], the methodological quality and risk basis of the included studies were evaluated as

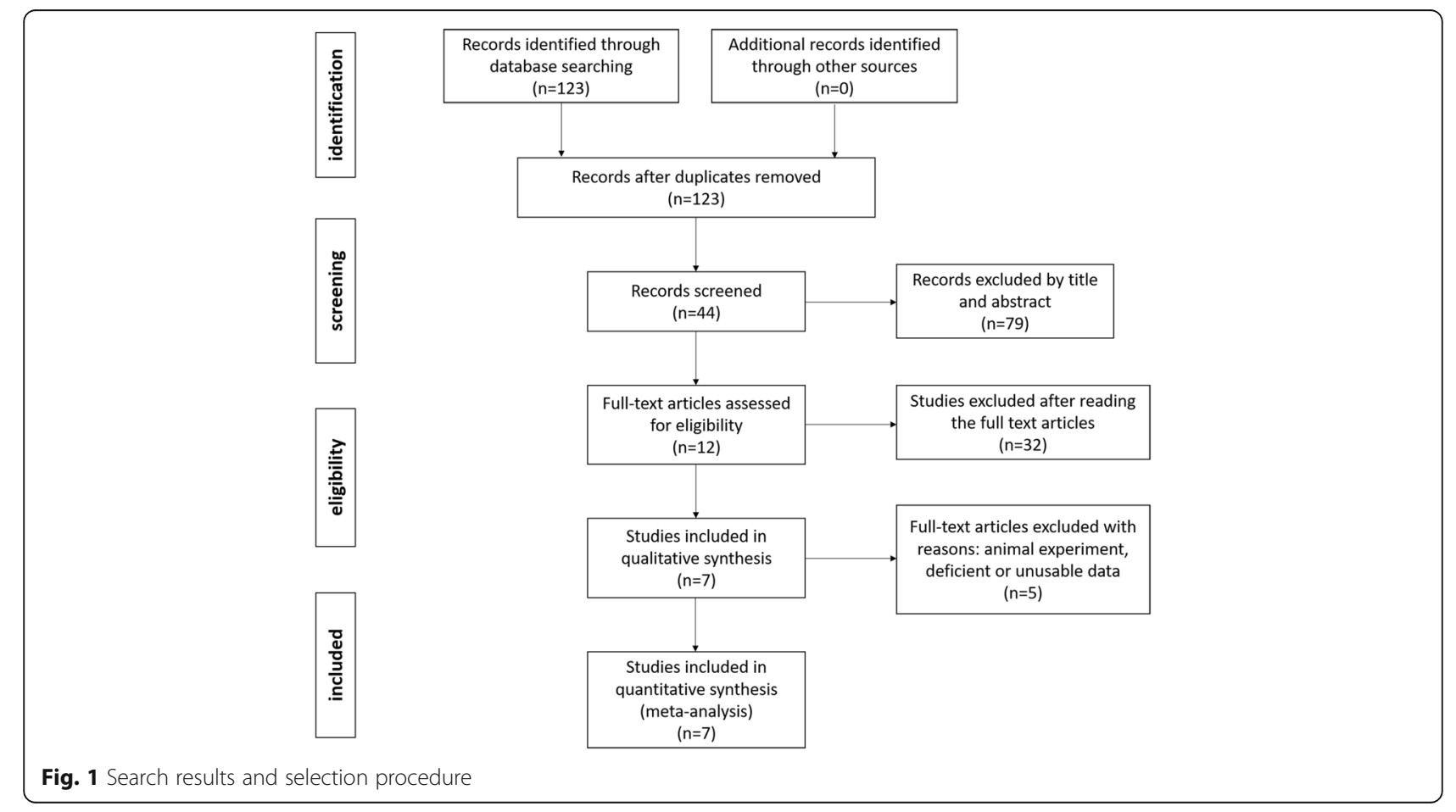




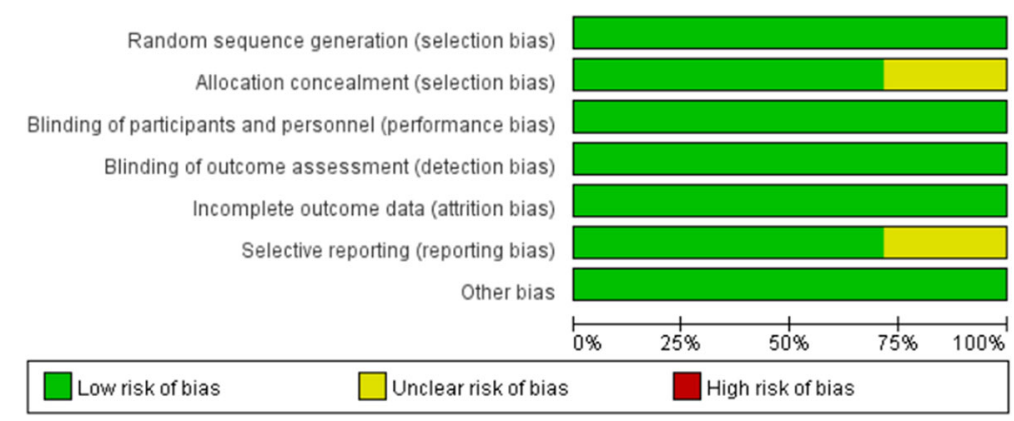

Fig. 2 Risk of bias graph

follows: (1) randomization method, (2) allocation concealment, (3) blind method of participant and outcome assessment, and (4) complete outcome data. The risk of bias can be seen in Figs. 2 and 3.

\section{Data extraction}

Data were extracted from the enrolled studies by two authors independently. The extracted data included

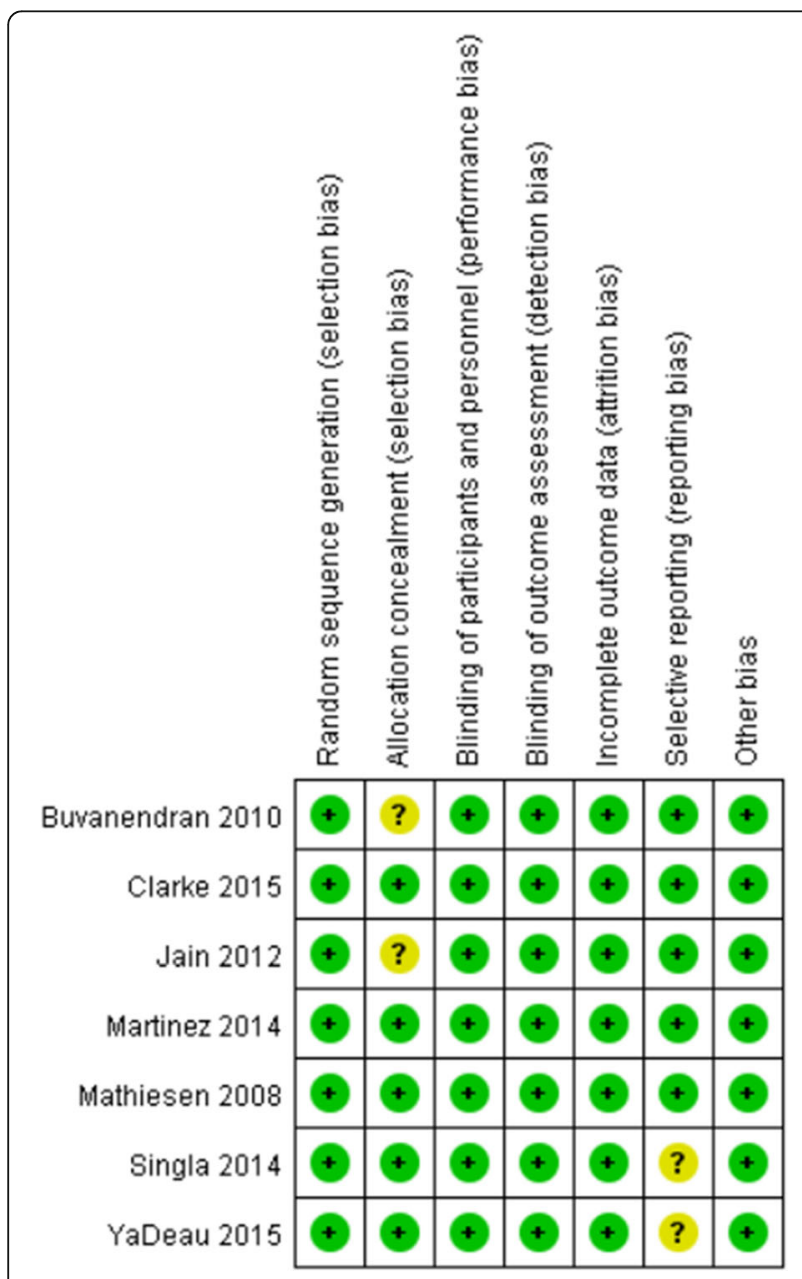

Fig. 3 Risk of bias summary publication data, title, first author's name, patient demographics, sample size, morphine consumption, pain scores, knee flexion degree, postoperative complications, and side effects (nausea, vomiting, pruritus, and dizziness).

\section{Data analysis and statistical methods}

The data were analyzed by Review Manager Software for Windows (RevMan Version 5.3, Copenhagen; The Nordic Cochrane Center, The Cochrane Collaboration, 2014). The means and standard deviations were applied to assess continuous variable outcomes with a 95\% confidence interval (CI), and relative risks and 95\% CIs were applied to assess dichotomous outcomes. Statistical heterogeneity was tested using the $I^{2}$ value and chi-squared test. A $P$ value $<0.05$ was considered statistically significant, and the random effect model was used for analysis. If $P$ values were $<0.05$ or $I^{2}>$ $50 \%$, indicating significant heterogeneity, the random effect model was applied.

\section{Result}

\section{Search result}

A total of 123 relevant articles were identified in the databases. Seven RCTs were included by reading the abstracts and entire article in detail. The overall methodological quality of the included studies was relatively high. All of the RCTs applied randomized, placebo-controlled, and doubleblind strategies, which reflected the high quality of the included literature. Baseline data were provided in all included studies without providing the intention to treat analysis. Finally, 823 patients were included in our metaanalysis. The patient characteristics are presented in Table 1. The sample sizes for each study ranged from 40 to 216 .

Randomization was stated in all RCTs through a computer-assisted program, and all of the RCTs used a double-blind methodology. Four studies [10-12, 14] were for TKA, while another three studies [15-17] were for THA, and there were 510 patients for TKA and 313 patients for THA. All of the articles had been published since 2008, and four of the articles had been published in the last 3 years. In experimental groups, 
Table 1 The general characteristic of the included studies

\begin{tabular}{|c|c|c|c|c|c|c|}
\hline Studies & $\begin{array}{l}\text { Cases } \\
\text { (Pre/P) }\end{array}$ & $\begin{array}{l}\text { Mean age } \\
\text { (Pre/P) }\end{array}$ & $\begin{array}{l}\text { Male patient } \\
\text { (Pre/P) }\end{array}$ & $\begin{array}{l}\text { Pregabalin dosage } \\
(\mathrm{mg} / \mathrm{d})\end{array}$ & $\begin{array}{l}\text { Reference } \\
\text { type }\end{array}$ & Postoperative analgesics \\
\hline Buvanendran et al. [14] & $106 / 110$ & $64 / 63$ & $29 / 36$ & 300 & $\mathrm{RCT}$ & $\begin{array}{l}\text { PCEA + celecoxib } 200 \mathrm{mg} \text { bid for } 3 \text { days while in the } \\
\text { hospital }\end{array}$ \\
\hline Jain et al. [10] & $20 / 20$ & $60 / 57$ & $9 / 5$ & 150 & $\mathrm{RCT}$ & $\begin{array}{l}\text { PCEA (containing bupivacaine } 0.0625 \% \text { and morphine } \\
0.05 \mathrm{mg} / \mathrm{ml} \text { ) }\end{array}$ \\
\hline Singla et al. [11] & $96 / 98$ & $64 / 63$ & $35 / 44$ & 300 & $\mathrm{RCT}$ & $\begin{array}{l}\text { PCA (morphine) + oral analgesia } 5 \mathrm{mg} \text { hydrocodone } \\
\text { bitartrate/500 mg acetaminophen tablets every } 4-6 \mathrm{~h}\end{array}$ \\
\hline YaDeau et al. [12] & $30 / 30$ & $68 / 66$ & $7 / 16$ & 300 & $\mathrm{RCT}$ & $\begin{array}{l}\text { PCEA (morphine) + meloxicam } 5 \mathrm{mg} \text { and oxycodone } \\
\text { paracetamol } 325 \mathrm{mg}\end{array}$ \\
\hline Mathiesen et al. [15] & $40 / 38$ & $67 / 66$ & $14 / 18$ & 300 & $\mathrm{RCT}$ & PCA (morphine) + acetaminophen $1 \mathrm{~g}$ tid \\
\hline Clarke et al. [16] & $83 / 79$ & $60 / 60$ & $41 / 41$ & 150 & $\mathrm{RCT}$ & $\begin{array}{l}\text { PCA (morphine) for } 24 \mathrm{~h}+\text { celecoxib } 200 \mathrm{mg} \text { bid, } \\
\text { oxycontin } 5 \mathrm{mg} \text { tid }\end{array}$ \\
\hline Martinez et al. [17] & $35 / 38$ & $64 / 64$ & $20 / 25$ & 150 & $\mathrm{RCT}$ & $\begin{array}{l}\text { PCA for } 48 \mathrm{~h} \text {, then paracetamol, non-steroidal anti- } \\
\text { inflammatory drugs and oral opioid }\end{array}$ \\
\hline
\end{tabular}

Pre/P pregabalin/placebo, QAS quality assessment score, $R C T$ randomized controlled trial, $P C T$ prospective control trials

each patient received pregabalin for corresponding dosage 1-2 $\mathrm{h}$ before surgery, and patients received pregabalin with dosages ranging from 150 to $300 \mathrm{mg}$ orally in the postoperative days. One TKA study used a dosage of $150 \mathrm{mg}$ pregabalin every day after surgery, and three studies used a $300 \mathrm{mg}$ dosage. YaDeau [12] conducted a multidose trial in which the dosage of pregabalin was $0,100,200$, and $300 \mathrm{mg}$ for each group every day. In this meta-analysis, we use the data of the $300 \mathrm{mg}$ as the experimental group and that of the $0 \mathrm{mg}$ as the control group. Singla [11] conducted a multicenter, randomized, double-blind, placebo-controlled trial; one part of the study was for TKA, two dosages (150, $300 \mathrm{mg} / \mathrm{d}$ ) were included, and we used the $300 \mathrm{mg}$ dosage for our meta-analysis. For THA studies, two studies used $150 \mathrm{mg} / \mathrm{d}$ pregabalin for the experimental group, and one study used $300 \mathrm{mg} / \mathrm{d}$. Postoperative analgesia included patient-controlled analgesia/patient-controlled epidural analgesia (PCA/PCEA), celecoxib, acetaminophen, non-steroidal anti-inflammatory drugs, and morphine. Postoperative analgesia details can be seen in Table 1.

\section{Meta-analysis results \\ Morphine consumption}

Based on six studies providing available data, we found that there was significant heterogeneity $\left(\chi^{2}=\right.$ 43.57, $\left.\mathrm{df}=5, \quad P<0.00001, I^{2}=89 \%\right)$. As depicted in Fig. 3, the pooled results produced a better outcome between the two groups according to a random effects model (MD $=-15.92,95 \% \mathrm{CI}$, [-26.56-5.29], $P=$ 0.003, Fig. 4). A subgroup analysis was performed for the morphine consumption (Table 2).

\begin{tabular}{|c|c|c|c|c|c|c|c|c|c|c|c|}
\hline \multirow{2}{*}{ Studv or Subgroup } & \multicolumn{3}{|c|}{ Experimental } & \multicolumn{2}{|c|}{ Control } & \multirow{2}{*}{ Total } & \multirow{2}{*}{ Weight } & \multirow{2}{*}{$\begin{array}{l}\text { Mean Difference } \\
\text { IV. Random, } 95 \% \mathrm{Cl}\end{array}$} & \multirow{2}{*}{\multicolumn{3}{|c|}{$\begin{array}{l}\text { Mean Difference } \\
\text { IV. Random, } 95 \% \mathrm{Cl}\end{array}$}} \\
\hline \multirow{2}{*}{\multicolumn{12}{|c|}{ 4.1.1 TKA }} \\
\hline & & & & & & & & & & & \\
\hline Buvanendran 2010 & 4.55 & 6.1 & 15 & 7.32 & 4,014 & 9 & $0.0 \%$ & $-2.77[-2625.20,2619.66]$ & & & \\
\hline Jain 2012 & 3.6 & 1.18 & 20 & 7.2 & 2.97 & 20 & $23.8 \%$ & $-3.60[-5.00,-2.20]$ & 불 & & \\
\hline YaDeau 2015 & 42.3 & 24.37 & 30 & 50 & 29.73 & 30 & $17.1 \%$ & $-7.70[-21.46,6.06]$ & $\longrightarrow-1$ & & \\
\hline Subtotal $(95 \% \mathrm{CI})$ & & & 65 & & & 59 & $40.9 \%$ & $-3.64[-5.04,-2.25]$ & $\boldsymbol{\theta}$ & & \\
\hline \multicolumn{12}{|c|}{$\begin{array}{l}\text { Heterogeneity: } \operatorname{Tau}^{2}=0.00 ; \mathrm{Chi}^{2}=0.34, \mathrm{df}=2(P=0.84) ; \mathrm{I}^{2}=0 \% \\
\text { Test for overall effect: } Z=5.12(P<0.00001)\end{array}$} \\
\hline \multicolumn{12}{|l|}{ 4.1.2 THA } \\
\hline Clarke 2015 & 40 & 21.85 & 83 & 53.8 & 22.22 & 79 & $21.8 \%$ & $-13.80[-20.59,-7.01]$ & & & \\
\hline Martinez 2014 & 44 & 20 & 35 & 77 & 36 & 38 & $17.5 \%$ & $-33.00[-46.23,-19.77]$ & & & \\
\hline Mathiesen 2008 & 23.9 & 13.9 & 40 & 49 & 27.8 & 38 & $19.9 \%$ & $-25.10[-34.93,-15.27]$ & & & \\
\hline Subtotal $(95 \% \mathrm{Cl})$ & & & 158 & & & 155 & $59.1 \%$ & $-22.90[-34.07,-11.74]$ & & & \\
\hline \multicolumn{12}{|c|}{$\begin{array}{l}\text { Heterogeneity: } \text { Tau }^{2}=71.65 ; \mathrm{Chi}^{2}=7.94, \mathrm{df}=2(P=0.02) ;\left.\right|^{2}=75 \% \\
\text { Test for overall effect: } Z=4.02(P<0.0001)\end{array}$} \\
\hline Total $(95 \% \mathrm{Cl})$ & & & 223 & & & 214 & $100.0 \%$ & $-15.92[-26.56,-5.29]$ & & & \\
\hline \multicolumn{9}{|c|}{$\begin{array}{l}\text { Heterogeneity: } \mathrm{Tau}^{2}=123.10 ; \mathrm{Chi}^{2}=43.57, \mathrm{df}=5(\mathrm{P}<0.00001) ; \mathrm{I}^{2}=89 \% \\
\text { Test for overall effect: } Z=2.93(P=0.003) \\
\text { Test for subaroun differences: } \mathrm{Chi}^{2}=11.26 . \mathrm{df}=1(\mathrm{P}=0.0008) . \mathrm{I}^{2}=91.1 \%\end{array}$} & $-50 \quad-25 \quad 0$ & Favours [control] & 50 \\
\hline \multicolumn{12}{|c|}{ Fig. 4 The effect of pregabalin illustrated by a forest plot diagram on mean morphine consumption } \\
\hline
\end{tabular}


Table 2 Subgroup analysis for morphine consumption

\begin{tabular}{llllll}
\hline $\begin{array}{l}\text { Subgroup } \\
\text { or } \\
\text { outcomes }\end{array}$ & Studies & \multicolumn{5}{l}{ Effect estimate } & & \\
\cline { 3 - 6 } & & $X^{2}$ & MD and 95\% Cl & $F^{2}(\%)$ & $P$ \\
\hline TKA & 3 & 0.34 & $-3.64(-5.04,-2.25)$ & 0 & 0.84 \\
THA & 3 & 7.94 & $-22.90(-34.07,-11.74)$ & 75 & 0.02 \\
\hline
\end{tabular}

\section{VAS score at rest}

\section{VAS at $24 h$}

A total of four component studies with 417 patients provided a VAS score at $24 \mathrm{~h}$ after surgery with rest. Our meta-analysis revealed that pregabalin produced a better outcome compared to the control group with rest at $24 \mathrm{~h}$ in terms of VAS score $(\mathrm{MD}=-0.66,95 \% \mathrm{CI}$ [-1.28-0.04], $P=0.04$, Fig. 5). We used a random effect model because statistical heterogeneity was high $\left(x^{2}=\right.$ $\left.14.59, \mathrm{df}=3, P=0.002, I^{2}=79 \%\right)$.

\section{VAS at $48 h$}

Only three studies with 275 patients reported the VAS score at $48 \mathrm{~h}$ postoperatively. Our meta-analysis found a highly significant difference between the two groups $(\mathrm{MD}=-0.95,95 \% \mathrm{CI},[-1.27-0.64], P<0.00001$, Fig. 6). A fixed-effect model was preferred because the statistical heterogeneity was low $\left(\chi^{2}=0.28, \mathrm{df}=2, P=0.87\right.$, $\left.I^{2}=0 \%\right)$.

\section{VAS at $72 h$}

Three studies stated the VAS score at $72 \mathrm{~h}$ postoperatively with rest, and our meta-analysis revealed that there was no significant difference between the two groups $(\mathrm{MD}=-0.56,95 \% \mathrm{CI},[-1.42-0.31], P=0.21$, Fig.7). We used a random effect model because of the significant statistical heterogeneity $\left(\chi^{2}=7.26, \mathrm{df}=2, P=\right.$ $\left.0.03, I^{2}=72 \%\right)$.

\section{VAS on movement}

Four studies in our meta-analysis reported the VAS score on movement at $24 \mathrm{~h}$, and the available data demonstrated that there was no significant difference between the two groups $(\mathrm{MD}=-0.54,95 \% \mathrm{CI},[-1.23-0.15], \quad P=0.13$, Fig. 8). The pooled results showed significant heterogeneity $\left(\chi^{2}=6.91\right.$, df $\left.=3, P=0.07, I^{2}=57 \%\right)$, and therefore, a random effect model was used.

\section{Knee flexion degree}

Only two studies [11, 14] provided the data of knee flexion degree measured at 24,48 , and $72 \mathrm{~h}$, respectively. The results demonstrated that there were significant differences between the two groups in TKA patients (MD $=4.89,95 \%$ CI, [3.41, 6.37], $P<0.00001$, Fig. 9). There was significant heterogeneity between the two groups based on the pooled data $\left(\chi^{2}=11.39, \mathrm{df}=5, P=0.04, I^{2}\right.$ $=56 \%)$, so we used a random effect model.

\section{Side effect}

We summarized four side effects of pregabalin after TKA and THA (Fig. 10). The results are presented in Table 3.

\section{Discussion}

This meta-analysis was performed to systematically review the literature and form a comprehensive understanding of the efficacy of pregabalin for the management of postoperative pain after TKA or THA. Our results indicated that the pregabalin played an important role in the VAS with rest at 24 and $48 \mathrm{~h}$, knee flexion degree, morphine consumption, and adverse events. No statistically significant differences were found in the VAS score with rest at $72 \mathrm{~h}$ and VAS on movement at $24 \mathrm{~h}$ between the pregabalin group and the control group.

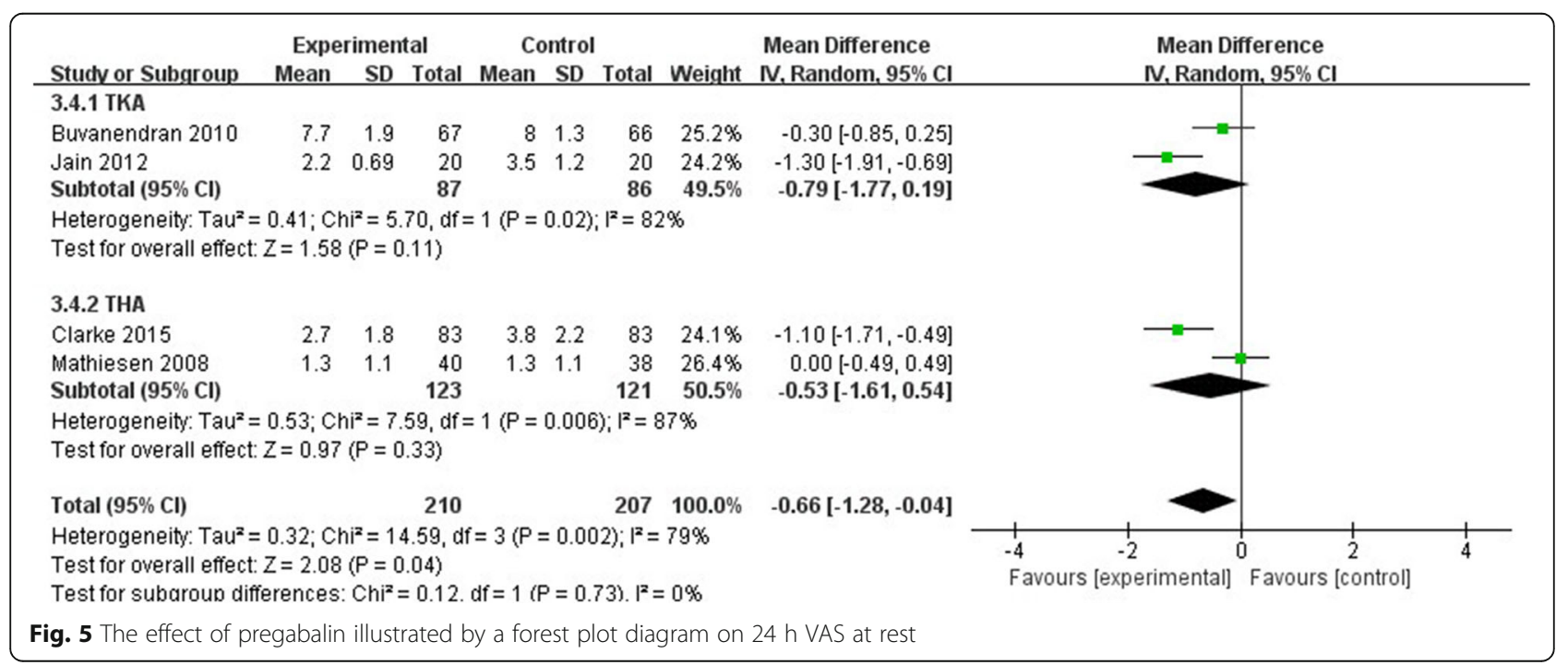




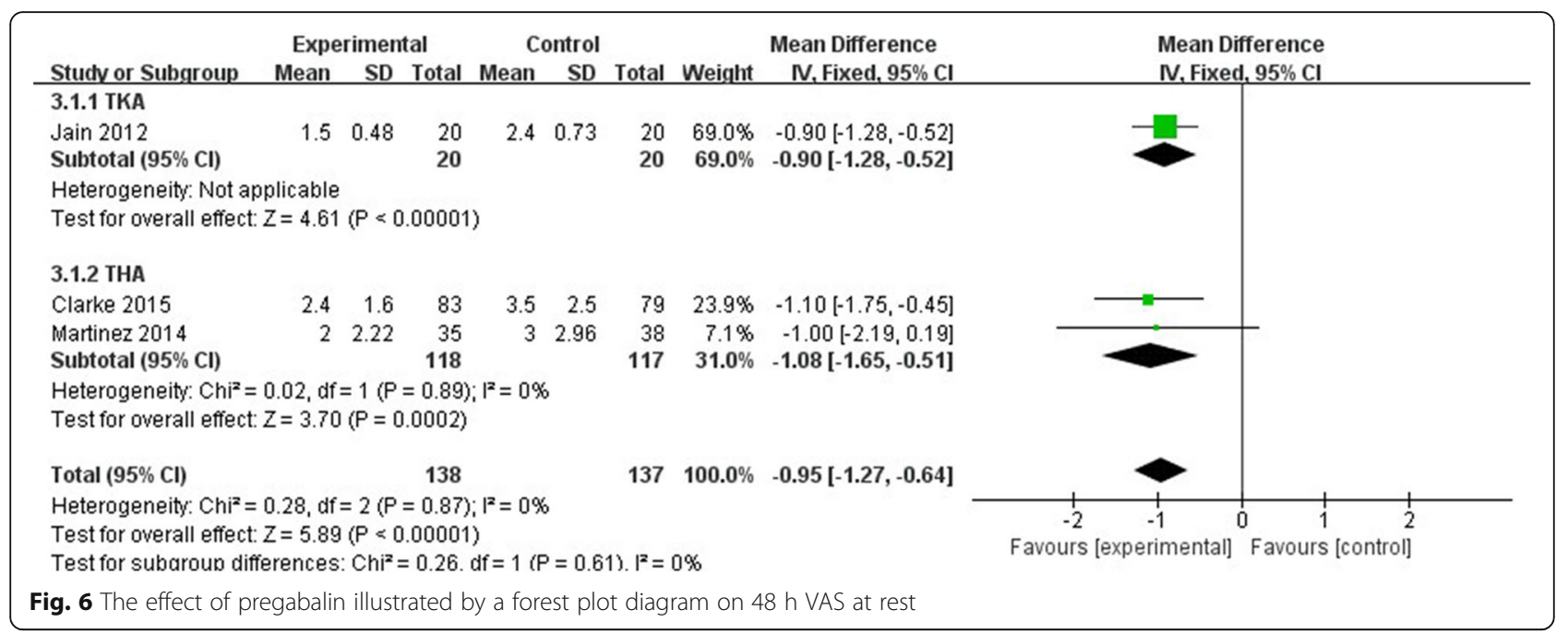

Mean morphine consumption was one of the primary outcomes in our study. Six studies documented mean morphine consumption, and significant difference was found between the pregabalin group and the control group in our meta-analysis $(P<0.003)$. We converted opioid use to morphine equivalents in all studies because different opioid drugs and units of measurement were used to record opioid consumption. It was very important to reduce opioid consumption after surgery because some patients would be easily addicted to opioid medications used after TKA or THA [18]. Our pooled data showed that pregabalin could decrease postoperative opioid consumption. This result agrees with those of other studies examining the administration of pregabalin $[10,14,19]$. Another meta-analysis showed that pregabalin can reduce 24-h morphine consumption in gynecologic, laparoscopic cholecystectomy, orthopedic, spine, and miscellaneous procedures [20]. These outcomes indicate that ideal analgesic effects can be achieved with less morphine consumption when pregabalin is used simultaneously.

The VAS pain score was a useful indicator for the assessment of pain with high value. A 10-cm-long moveable ruler was used to test the pain level for patients after TKA or THA (0-10, 0 was no pain and 10 was unbearable pain). In our study, 24, 48, and $72 \mathrm{~h}$ at rest and $24 \mathrm{~h}$ of movement postoperatively were selected as the point-in-time for comparison. This meta-analysis showed significant difference between 24 and 48 h VAS scores at rest, which indicates that pregabalin can effectively relieve postoperative pain at rest. Jokela et al. [21] found that premedication with 75 or $150 \mathrm{mg}$ pregabalin significantly reduced the VAS score for postoperative pain at $24 \mathrm{~h}$ after laparoscopic gynecologic surgery $(P<$ $0.05)$ when compared with diazepam $5 \mathrm{mg}$. Some other studies [22, 23] have reported that pregabalin administration could reduce the VAS score at $24 \mathrm{~h}$ compared with placebo postoperatively. Gianesello [24] showed

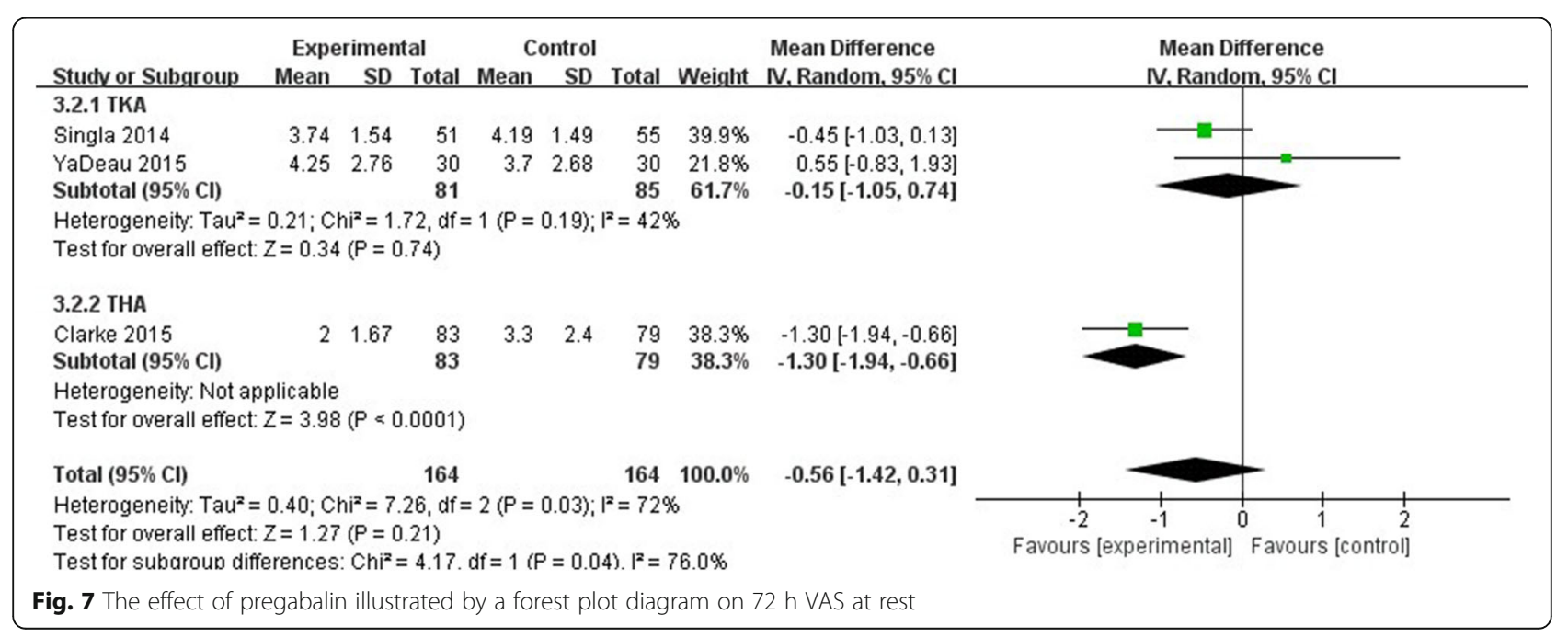




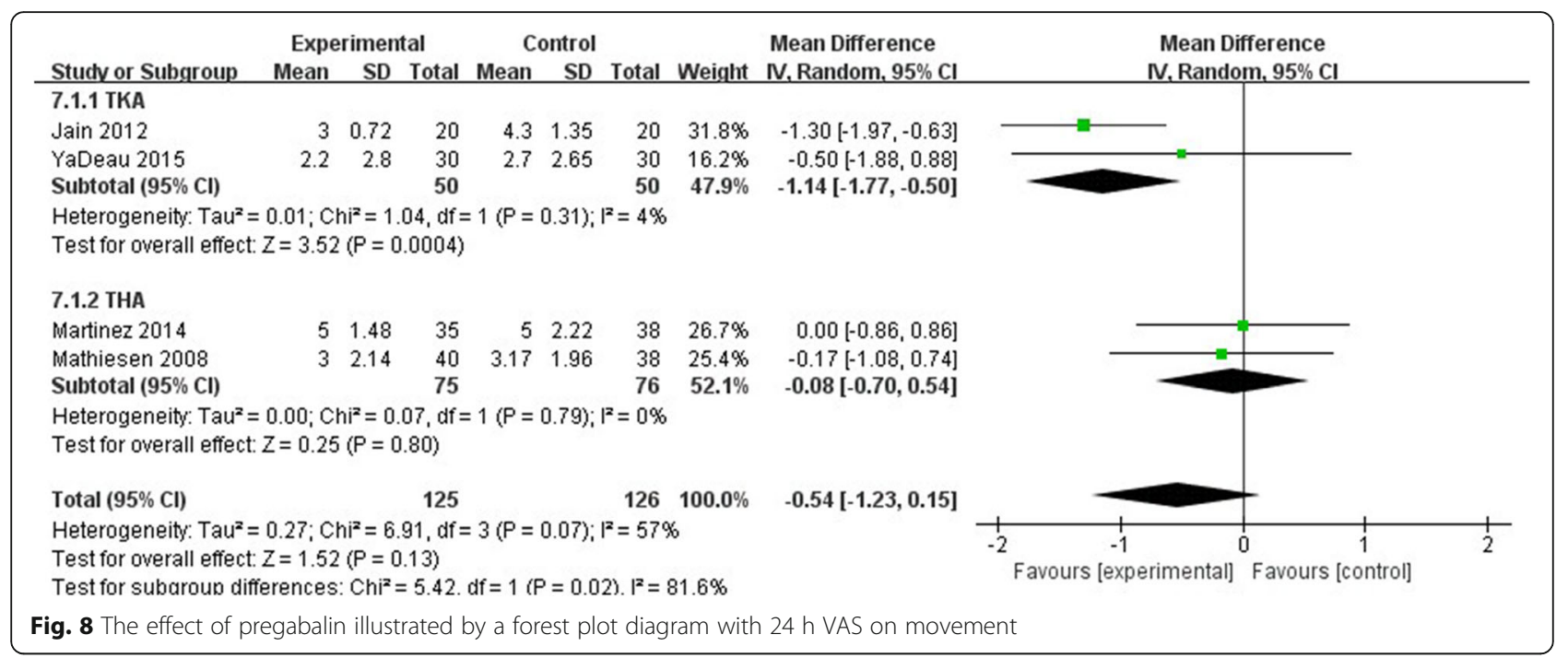

that perioperative administration of pregabalin at a dose of $300 \mathrm{mg}$ every day resulted in a significant reduction in VAS scores at $48 \mathrm{~h}$ postoperatively for patients undergoing major spinal surgery. These outcomes demonstrate that administration of pregabalin could reduce VAS score at 24 and $48 \mathrm{~h}$ with rest after surgery. The VAS at $72 \mathrm{~h}$ with rest postoperatively was not significant in our pooled data. The decreased benefits of pregabalin on pain during movement could be explained by the short mean elimination half-life of pregabalin [25]. No significant difference was found in VAS on movement at $24 \mathrm{~h}$, and the result was similar to another meta-analysis of pregabalin for tonsillectomy [26]. One explanation for this could be that the movement of body intensified the pain after surgery. Additionally, the sample size was small, with only four included studies. Therefore, we could not determine the effect of pregabalin for TKA and THA at $24 \mathrm{~h}$ of movement postoperatively. Although no significant reduction in VAS score at $72 \mathrm{~h}$ with rest and at $24 \mathrm{~h}$ on movement postoperatively, the score of the pregabalin group was lower than that of the control group in most studies. In summary, preoperative administration of pregabalin could improve acute pain control after TKA and THA.

Knee flexion degree was a valuable indicator to evaluate the motion of knee joints and functional recovery

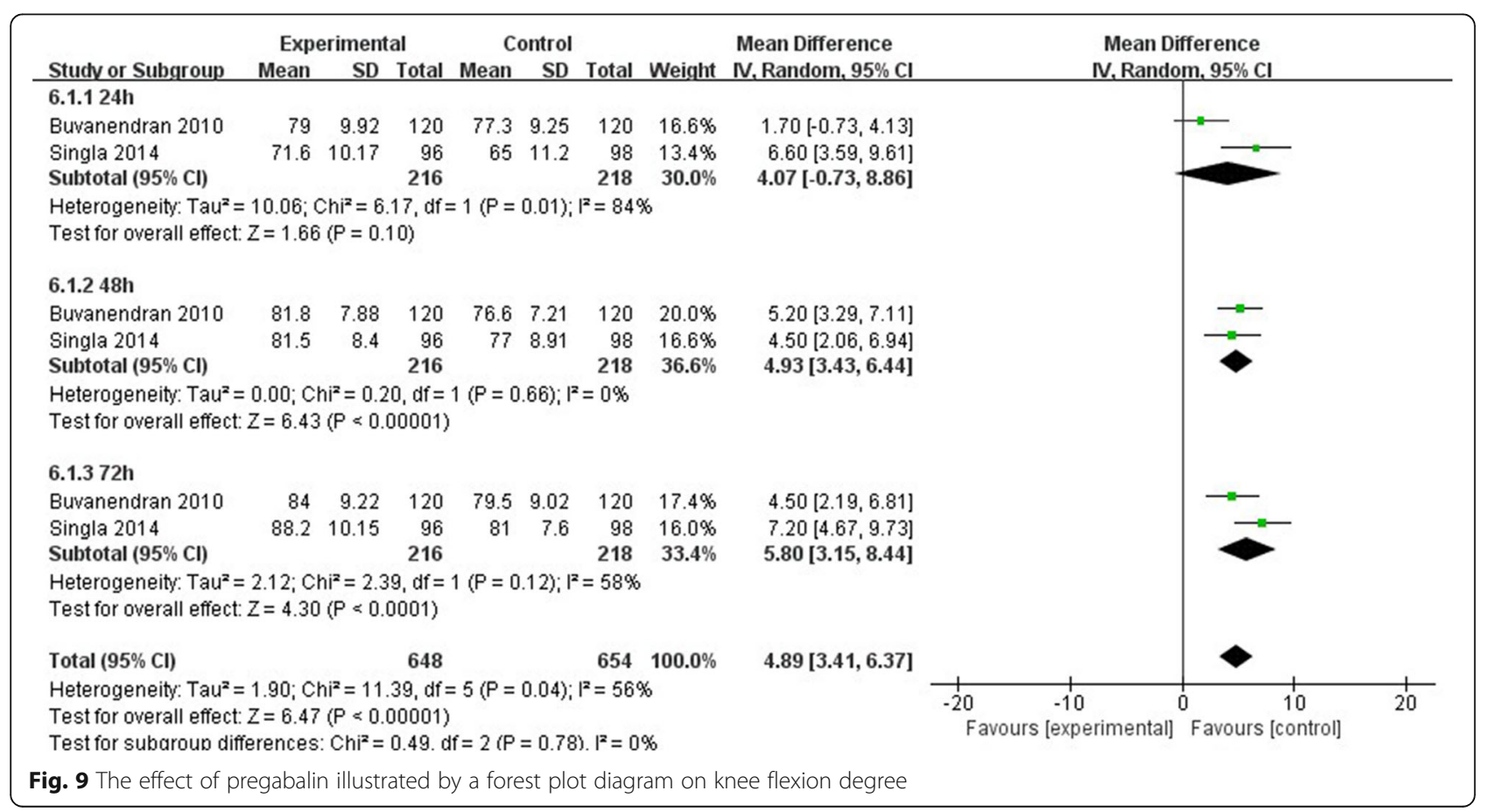




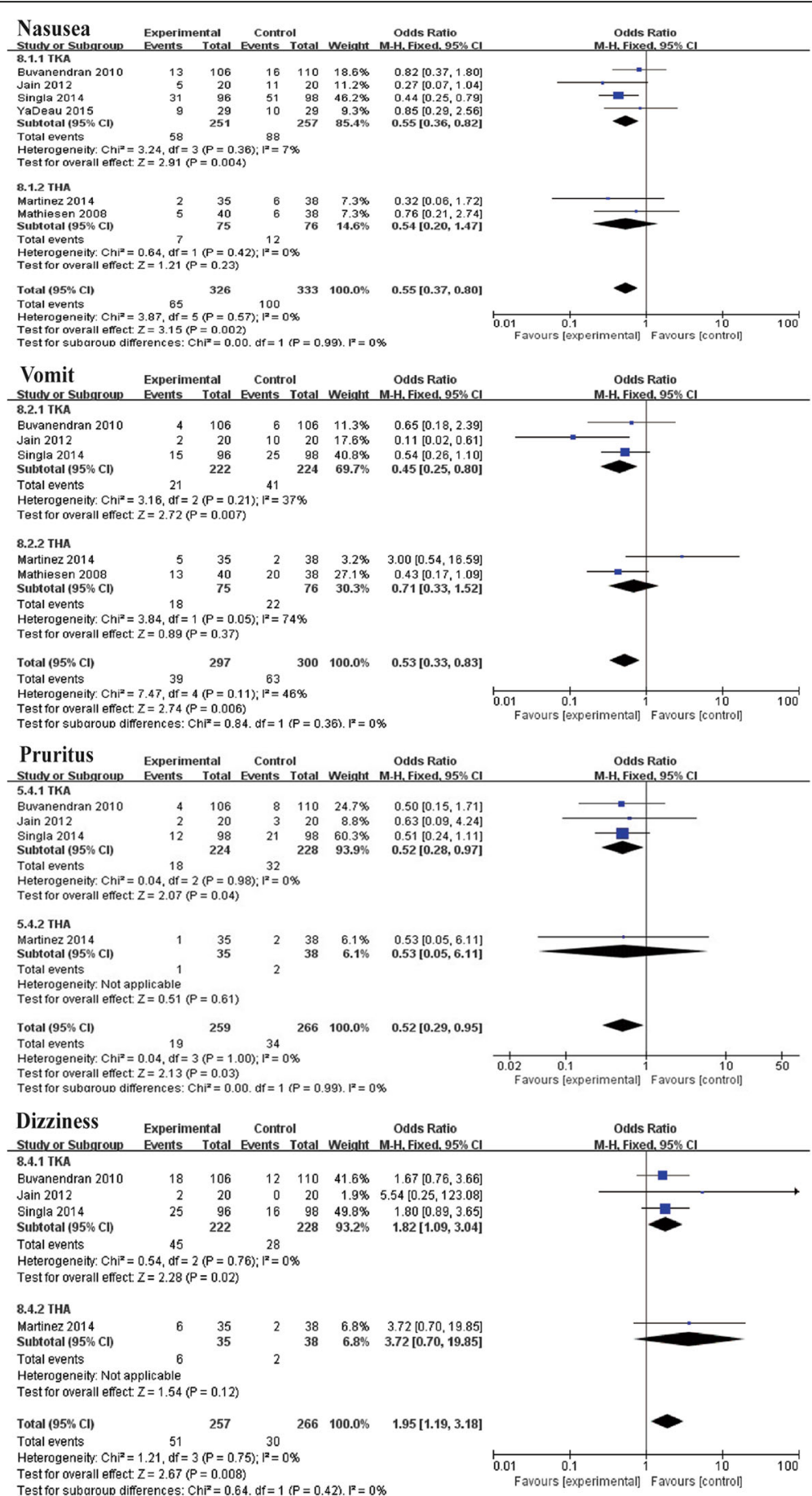

Fig. 10 The effect of pregabalin illustrated by a forest plot diagram on side effects (nausea, vomiting, pruritus, and dizziness)

$[27,28]$. We established a subgroup to investigate the reasons of heterogeneity and the data of different time periods. Our pooled data showed that the pregabalin groups can enhance the knee range of motion effectively $(P<0.00001)$. Buvanendran [14] demonstrated that pregabalin shortened the time to achieve normal knee range of motion (ROM). He thought this beneficial effect on knee functions at the time of discharge facilitated nearly full functionality. Pregabalin was shown to improve pain control, and less pain can lead to more extensive activities, which may be the reason for the improvement of knee function. Singla [11] showed that passive knee range of motion for the operated knee was greater for the $300 \mathrm{mg} / \mathrm{d}$ pregabalin group compared with placebo 
Table 3 Results of side effect

\begin{tabular}{llcllllll}
\hline Outcome & Studies & \multicolumn{2}{l}{ Overall effect } & & & \multicolumn{2}{c}{ Heterogeneity } \\
\cline { 3 - 4 } & & Effect estimate & $95 \% \mathrm{Cl}$ & $P$ value & & $P(\%)$ & $P$ value \\
\hline Nausea & 6 & 0.55 & $0.37,0.80$ & 0.002 & & 0 & 0.57 \\
Vomits & 5 & 0.53 & $0.33,0.83$ & 0.006 & 46 & 0.11 \\
Pruritus & 4 & 0.52 & $0.29,0.95$ & 0.03 & 0 & 1.0 \\
Dizziness & 4 & 1.95 & $1.19,3.18$ & 0.008 & 0 & 0.75 \\
\hline
\end{tabular}

at $24,72,96,120 \mathrm{~h}$, and at week 4 post-TKA, and active ROM (upon flexion) was significantly greater in the $300 \mathrm{mg} / \mathrm{d}$ pregabalin group compared with that of the placebo only group at week 4 . Thus, according to this result, we concluded that perioperative pregabalin consumption had beneficial effects on improving knee function.

Postoperative nausea and vomiting were usually caused by different anesthetic modes that were mostly related to the gastrointestinal system [29]. Our pooled data showed that postoperative oral pregabalin could decrease the incidence of nausea and vomiting. The same results were reported in another meta-analysis [30], which indicated that preoperative pregabalin is associated with a significant reduction of postoperative nausea and vomiting. Based on these outcomes, postoperative administration of pregabalin has been shown to reduce nausea and vomiting. Pruritus is another side effect during the administration of pregabalin. As shown in Fig. 10, pregabalin can significantly decrease the incident rate of postoperative pruritus. Şavk [31] suggested that pregabalin at a daily dose of $150 \mathrm{mg}$ was effective in reducing chronic pruritus. Dizziness was the most common adverse effect profile of pregabalin. The pooled data showed that the pregabalin would increase the incident rate of dizziness. Griffin [32] reported that dizziness, fatigue, and somnolence were among the most common adverse effects of pregabalin. In summary, we found that pregabalin can effectively reduce the incidence of nausea, vomiting, and pruritus, but it can increase the incidence of dizziness.

Our meta-analysis has the following potential limitations: (1) only seven RCTs were selected in our metaanalysis; if more studies were included, statistical efficacy would increase. (2) The follow-up period of patients was too short in some of the trials. Most patients were followed up only in the short term. This may have resulted in underreporting of some useful information. (3) There were not sufficient data, such as neuropathic pain, sleep disturbance, time to discharge, and physical composite score above. (4) Risk of bias cannot be avoided in this meta-analysis because only English publications were included. (5) Almost all the included studies were published by anesthetists, and some important details usually considered by orthopedics, such as surgical approach, methods of fixation, technique of incision, and type of implant were not reported in those papers. It is believed that all of these factors have the ability to change the degree of postoperative pain, and that they need to be taken into account in future studies.

Although this study has several limitations, it is the first systematic review to evaluate the efficacy of pregabalin with placebo in primary TKA and THA. Available articles were screened strictly; hence, the articles adopted for the final review were of high quality. However, more high-quality literature should be included to elevate statistical efficacy and increase sample size.

\section{Conclusions}

Our meta-analysis indicated that pregabalin could improve pain control at 24 and $48 \mathrm{~h}$ with rest, reduce morphine consumption, and improve the knee flexion degree as well as decreasing the incident rate of nausea, vomiting, and pruritus and increasing the incident rate of dizziness after TKA and THA but could not improve the pain control at $72 \mathrm{~h}$ with rest. In summary, the use of pregabalin may be a valuable asset in pain management within first $48 \mathrm{~h}$ after TKA and THA. However, future studies regarding doses and pregabalin medication are required.

\section{Appendix 1}

\#1 Total Knee Replacement

\#2 Total Knee Arthroplasty

\#3 “Arthroplasty, Replacement, Knee" [Mesh]

\#4. Search (\#1 OR \#2) OR \#3

\#5 Total Hip Replacement

\#6 Total Hip Arthroplasty

\#7 “Arthroplasty, Replacement, Hip” [Mesh]

\#8 Search (\#5 OR \#6) OR \#7

\#9 Search (\#4 OR \#8)

\#10“Pregabalin" [Mesh]

\#11 random*

\#12 "Randomized Controlled Trial” [Publication Type]

\#13 "Randomized Controlled Trials as Topic" [Mesh]

\#14 Search (\#11 OR \#12 OR \#13)

\#15 Search (\#9 AND \#10 AND \# 14)

\section{Abbreviations}

Cl: Confidence interval; GABA: $y$-Aminobutyric acid; RCT: Randomized controlled trial; ROM: Range of motion; THA: Total hip arthroplasty; TKA: Total knee arthroplasty; VAS: Visual analogue scale

\section{Acknowledgements \\ None.}

\section{Funding}

This study was funded by the National Natural Science Foundation of China (NO. 81572154), Tianjin Municipal Health Bureau of Science and Technology Research Projects (15KG123), and Ministry of Medical Health and Health

Technology Development Research Center (W2013ZT058). 


\section{Availability of data and materials}

As this paper is a meta-analysis, there are no patient datasets, and all the raw data can be seen in the included figures.

\section{Authors' contributions}

X-LM designed the study and proofread the manuscript. FL, JM, and MK conceived of and designed the study, collected and analyzed the data, and wrote the paper. XJ and YW collected and analyzed the data. LS, XZ, and BL revised the draft and generated the figures. All authors read and approved the final manuscript.

\section{Competing interests}

The authors declare that they have no conflict of interests.

\section{Consent for publication}

Not applicable.

\section{Ethics approval and consent to participate}

This article is not involved in ethical requirements.

\section{Guarantor}

Xinlong Ma.

\section{Author details}

${ }^{1}$ Biomechanics Labs of Orthopaedics Institute, Tianjin Hospital, Tianjin 300050, People's Republic of China. ${ }^{2}$ Tianjin Medical University, Tianjin 300070, People's Republic of China.

\section{Received: 29 September 2016 Accepted: 9 February 2017}

\section{Published online: 24 March 2017}

\section{References}

1. Kahn TL, Soheili A, Schwarzkopf R. Outcomes of total knee arthroplasty in relation to preoperative patient-reported and radiographic measures: data from the osteoarthritis initiative. Geriatr Orthop Surg Rehabil. 2013;4(4):117-26.

2. Alshryda S, et al. A systematic review and meta-analysis of the topical administration of tranexamic acid in total hip and knee replacement. Bone Joint J. 2014;96-B(8):1005-15.

3. Bashinskaya B, et al. Arthroplasty utilization in the United States is predicted by age-specific population groups. ISRN Orthop. 2012;2012.

4. Benyamin R, et al. Opioid complications and side effects. Pain Physician. 2008;11(2 Suppl):S105-20.

5. Kehlet H, Dahl JB. The value of "multimodal" or "balanced analgesia" in postoperative pain treatment. Anesth Analg. 1993;77(5):1048-56.

6. Gray P. Pregabalin in the management of central neuropathic pain. Expert Opin Pharmacother. 2007:8(17):3035-41.

7. O'Connor AB, Dworkin RH. Treatment of neuropathic pain: an overview of recent quidelines. Am J Med. 2009;122(10 Suppl):S22-32.

8. $\quad \mathrm{Li} Z$, et al. Pregabalin is a potent and selective ligand for $a 2 \delta-1$ and $a 2 \delta-2$ calcium channel subunits. Eur J Pharmacol. 2011;667(1-3):80-90.

9. Ryvlin P, Perucca E, Rheims S. Pregabalin for the management of partial epilepsy. Neuropsychiatr Dis Treat. 2008;4(6):1211-24.

10. Jain $P$, et al. Evaluation of efficacy of oral pregabalin in reducing postoperative pain in patients undergoing total knee arthroplasty. Indian J Orthop. 2012:46(6):646-52.

11. Singla NK, et al. Pregabalin for the treatment of postoperative pain: results from three controlled trials using different surgical models. J Pain Res. 2015;8:9-20.

12. YaDeau JT, et al. Pregabalin and pain after total knee arthroplasty: a doubleblind, randomized, placebo-controlled, multidose trial. Br J Anaesth. 2015: 115(2):285-93.

13. Wang T, et al. Analysis of risk factors for femoral head necrosis after internal fixation in femoral neck fractures. Orthopedics. 2014;37(12):e1117-23.

14. Buvanendran $\mathrm{A}$, et al. Perioperative oral pregabalin reduces chronic pain after total knee arthroplasty: a prospective, randomized, controlled trial. Anesth Analg. 2010;110(1):199-207.

15. Mathiesen $\mathrm{O}$, et al. Pregabalin and dexamethasone for postoperative pain control: a randomized controlled study in hip arthroplasty. Br J Anaesth. 2008:101(4):535-41.

16. Clarke $\mathrm{H}$, et al. Pregabalin reduces postoperative opioid consumption and pain for 1 week after hospital discharge, but does not affect function at 6 weeks or 3 months after total hip arthroplasty. Br J Anaesth. 2015;115(6):903-11.
17. Martinez $V$, et al. The analgesic efficiency of combined pregabalin and ketamine for total hip arthroplasty: a randomised, double-blind, controlled study. Anaesthesia. 2014;69(1):46-52.

18. Prommer E, Ficek B. Management of pain in the elderly at the end of life. Drugs Aging. 2012;29(4):285-305.

19. Sawan $\mathrm{H}$, et al. Pregabalin reduces opioid consumption and improves outcome in chronic pain patients undergoing total knee arthroplasty. Phys Sportsmed. 2014;42(2):10-8.

20. Lam DM, et al. Efficacy of pregabalin in acute postoperative pain under different surgical categories: a meta-analysis. Medicine (Baltimore). 2015: 94(46):e1944.

21. Jokela R, et al. Premedication with pregabalin 75 or $150 \mathrm{mg}$ with ibuprofen to control pain after day-case gynaecological laparoscopic surgery. $\mathrm{Br} J$ Anaesth. 2008;100(6):834-40.

22. Nutthachote $P$, et al. A randomized, double-blind, placebo-controlled trial of oral pregabalin for relief of shoulder pain after laparoscopic gynecologic surgery. J Minim Invasive Gynecol. 2014:21(4):669-73.

23. Mathiesen $\mathrm{O}$, et al. Pregabalin and dexamethasone improves post-operative pain treatment after tonsillectomy. Acta Anaesthesiol Scand. 2011;55(3):297-305.

24. Gianesello $L$, et al. Perioperative pregabalin for postoperative pain control and quality of life after major spinal surgery. J Neurosurg Anesthesiol. 2012;24(2):121-6.

25. Owen RT. Pregabalin: its efficacy, safety and tolerability profile in generalized anxiety. Drugs Today (Barc). 2007:43(9):601-10.

26. Hwang $\mathrm{SH}$, et al. The efficacy of gabapentin/pregabalin in improving pain after tonsillectomy: a meta-analysis. Laryngoscope. 2016;126(2):357-66.

27. Busch CA, et al. Efficacy of periarticular multimodal drug injection in total knee arthroplasty. A randomized trial. J Bone Joint Surg Am. 2006;88(5):959-63.

28. Colwell CJ, Morris BA. The influence of continuous passive motion on the results of total knee arthroplasty. Clin Orthop Relat Res. 1992;276:225-8.

29. Worland $\mathrm{RL}$, et al. Home continuous passive motion machine versus professional physical therapy following total knee replacement. J Arthroplasty. 1998;13(7):784-7.

30. Grant MC, et al. The effect of preoperative pregabalin on postoperative nausea and vomiting: a meta-analysis. Anesth Analg. 2016;123(5):1100-7.

31. Savk E. Neurologic itch management. Curr Probl Dermatol. 2016;50:116-23.

32. Griffin E, Brown JN. Pregabalin for the treatment of restless legs syndrome. Ann Pharmacother. 2016;50(7):586-91.

\section{Submit your next manuscript to BioMed Central and we will help you at every step:}

- We accept pre-submission inquiries

- Our selector tool helps you to find the most relevant journal

- We provide round the clock customer support

- Convenient online submission

- Thorough peer review

- Inclusion in PubMed and all major indexing services

- Maximum visibility for your research

Submit your manuscript at www.biomedcentral.com/submit
Biomed Central 